\title{
La negociación de la sospecha
}

\section{The negotiation of suspicion}

\author{
Piccato, Pablo (20 i i), CiUdad de sospechosos: cRimen en la CiUdad \\ de México, 1900-1931, Centro de Investigaciones y Estudios \\ Superiores en Antropología Social-Publicaciones de la Casa \\ Chata, MÉxico, 394 pp., isbn: 978-607-486-074-0.
}

Hay libros que ameritan muchas presentaciones y sin lugar a dudas éste es uno de ellos. No sólo porque el crimen en la ciudad de México resulta un tema de todos los días, sino por las sugerentes lecturas que posibilita el trabajo de Pablo Piccato.

En una original intersección de campos, el libro trata el crimen y la ciudad. Los sospechosos son la parte viva de la urbe y constituyen una comunidad donde cada quien tiene su sitio. Como parte de la identidad capitalina, la delincuencia urbana, sus discursos, sus prácticas y sus espacios sitúan al lector en el tema y le permiten apreciar el complejo análisis que resulta de una sólida investigación en archivos, pero sobre todo, de la mirada crítica de los documentos que elude la versión engañosa de los policías y los ladrones, de las fuentes cuantitativas y de las atractivas narraciones que construyen casos espectaculares de asesinos seriales. La apuesta del autor es entender el crimen y el castigo que impera en las ciudades, con una perspectiva histórica, tomando como escenario a la ciudad de México en las primeras décadas del siglo xx.

Del código penal de 1871 al código de 1931 criminólogos, penalistas y hombres del derecho se ajustaron a las transformaciones que supusieron el proceso de modernización urbana y la Revolución mexicana. ¿Quiénes fueron los sospechosos? ¿cómo se transgredió el orden establecido? ¿de qué manera se atentó contra el progreso, la moral, el honor? ¿cuáles eran las motivaciones de aquellos que cometían un crimen y de los que lo juzgaban? Son cuestiones que lejos de una respuesta fácil, muestran que todo depende del universo de análisis y en esto el autor no escatima: la familia, el barrio, la vecindad, la cárcel, el juzgado, la calle, las cantinas, los comercios, son todos, complejos espacios urbanos en los que interactúan los habitantes de la capital para tejer redes de solidaridad en las que se negocia la sospecha.

En la ciudad vigilada Pablo Piccato evidencia la singularidad de la disputa por el espacio urbano. La segregación de los territorios considerados peligrosos se asocian con la pobreza y la suciedad. Pero la frontera entre los lugares seguros e inseguros se difumina a partir de los usos que 
los habitantes de la capital hacen de sus espacios. Sin despreciar el protagonismo de las élites, que anhelaban barrios y colonias limpias de delincuentes, Piccato también se acerca a los límites materiales que conlleva poner en práctica el orden y la civilidad. La policía, como institución, está trastocada por las reglas y las normas del deber ser y del poder hacer. Así, el policía que se integró al cuerpo de gendarmes, indisciplinado y mal pagado, actúa como un intermediario involuntario de instituciones y comunidades, de los anhelos y las prácticas, de los criminales y de las víctimas.

Reconocer el juego social de este intermediario es, en mi opinión, uno de los aciertos metodológicos que está presente, sobre todo, en la primera parte del libro, pues apuntala una tarea indispensable para las llamadas nuevas historiografías de entreverar el análisis de los individuos y de las estructuras, muestra cómo ha sido provechoso cotejar las representaciones de la criminalidad y de los delincuentes con las prácticas de los penalistas y de las políticas públicas frente al crimen; también contribuye a repensar las experiencia de las élites según lo que ha significado para ellos corregir al delincuente $y$, en una perspectiva desde abajo, explora el valor que concedieron los sospechosos a la redención y al castigo.

Aquí me parece necesario un paréntesis respecto del desarrollo de la criminología en México, que si bien, como expone el autor, el campo de análisis ha sido vasto, la profesionalización en esta materia no respondió a las necesidades del país. En vista de lo anterior nos preguntamos, ¿̨cómo se conjugó el impacto limitado de la criminología con la intervención estatal en la prevención del crimen? Para esto, el texto brinda respuestas de documento en documento. Del Porfiriato a la posrevolución, una reforma social fallida emanó de políticas públicas optimistas, pero poco coherentes.

En la segunda parte del libro, Pablo Piccato muestra el rostro de las víctimas y de los criminales. En el mundo del crimen, el abuso, la violación y el robo son el eje de las relaciones familiares, entre vecinos, de los patrones y sus empleados. Algunos cambios trastocan las relaciones sociales en el ámbito cotidiano de lo público y lo privado: la afirmación de la integridad masculina a partir del uso de las armas se reafirma del cuchillo decimonónico a la pistola del revolucionario. Pero los códigos no escritos definen, también, la dinámica de las formas de la violencia urbana para dejar poco a la casualidad. Así, los golpes se toleran siempre y cuando la jerarquía social se mantenga y los esposos, los padres y los hijos resuelvan sus diferencias; las heridas en la cara de una prostituta son demostraciones de poder de su proxeneta, y las mujeres pobres pueden involucrarse en crímenes violentos cuando está en juego su reputación. La irracionalidad de los pobres, de los amantes despechados, de los empleados ofendidos 
son argumentos clave en la negociación para eludir el encierro. Lo cierto es que más allá de los celos que arrebataban, por ejemplo, al matamujeres del pueblo, la violencia inherente de los pobres, apenas debatida como un patrón de comportamiento, se empleó como argumento de los periodistas, de los jueces, de los policías, pero también de los acusados, que deliberadamente reformulaban el discurso de la indigencia para eximirse de la pena.

Poder, sexo, amor y dinero, como motivaciones de la violencia urbana, deben entenderse en contextos amplios y flexibles. Para explicar las inconsistencias y las singularidades del horrendo caso de la calle de la amargura o del violador Francisco Guerrero, El Chalequero, Pablo Piccato traduce el lenguaje del pasado al del presente para acortar la distancia de las experiencias criminales y victimarias de los habitantes de la ciudad a principios del siglo pasado. Entre otros, el lector de este libro sabrá, entonces, a qué está dispuesta una mujer por una promesa de matrimonio y cuáles son las armas que puede utilizar para resarcir la falta de la promesa incumplida, según lo que considera como justo. Cuando una joven, timada por un mal hombre, entrega su virginidad a cambio de la propuesta de ser desposada, el engaño se podía pagar con la vida.

En el binomio crimen y castigo, la tercera parte se ocupa de la sanción, de la pena aplicada al sentenciado y del castigo social que infligieron desde las instituciones penales los legisladores y los reformadores sociales, quienes con el propósito de desterrar el crimen de las urbes, ampliaron el espectro de la sospecha sobre los habitantes de la ciudad. El paulatino desuso de la leva dio paso a los campos de trabajo en Valle Nacional, Oaxaca, Yucatán y finalmente en las Islas Marías, que consolidó una de las reformas más significativas del Porfiriato sobre procedimientos penales en 1894 y cuya vigencia se mantuvo hasta la década de los treinta, cuando las campañas del destierro de la delincuencia fueron cuestionadas desde el Ejecutivo.

El castigo era una cuestión de definiciones y no se aplicó igual para todos. Las definiciones acompañaban a las disposiciones de las leyes y de los códigos existentes. De esta manera, la categoría de ratero posibilita un sinnúmero de condenas discrecionales. Página a página, con una espléndida narrativa que recoge las formas y los sentidos del lenguaje de la época, Pablo Piccato expone que a la penitenciaria llegaba quien tenía cara de ratero, pero también quien engañaba y se hacía pasar como persona decente, era probable que las aprehensiones se hicieran en ciertas zonas de la urbe donde pululaba esta población rastrera, que como plaga reproducía su oficio y promovía la especialización del hurto. Esta ilusión narrativa que nos permite ver los acontecimientos del pasado desde la perspectiva de aquellos que lo vivieron, no deja de lado las transforma- 
ciones y, en aras de la especialización, el típico caco incorpora a su oficio nuevos elementos tecnológicos y complejas formas de socialización que llegan también a los altos mandos de las autoridades del país. El surgimiento de bandas, como la del automóvil gris, evidencia no sólo la corrupción del sistema, sino el tránsito que supuso la modernización en la capital del país a principios del siglo xx.

La experiencia común de los prisioneros, de los vecinos de Tepito, de las prostitutas de la Merced, de los ciudadanos comunes y corrientes, construye una identidad a partir de intereses compartidos y la articula contra otros cuyos intereses son distintos. Expresiones de supuestos morales colectivos se descubren en un espacio urbano en el que se manifiesta el consenso. En México las comunidades afrentan a la autoridad según un sistema de valores compartido, así se permite una rińa callejera y se protege al sospechoso conocido en un intento por subsistir en la ciudad. La comunidad articula mecanismos de negociación que se van debilitando frente a la consolidación de las instituciones de los gobiernos posrevolucionarios. Pablo Piccato va desentrañando frente al lector a la comunidad como un actor más que forja en la capital de la república un sentido propio de justicia. El autor no ha tenido el propósito de recorrer su investigación al Siglo de Oro español, pero en el tema de la justicia que clama el pueblo, parece inevitable evocar la clásica escena de Félix Lope de Vega en la que el pueblo oculta el asesinato de la autoridad y a la pregunta del juez "¿Quién mató al Comendador?", al unísono responden "Fuenteovejuna, Señor", “Quién es 'Fuenteovejuna'?” "Todo el pueblo, Señor". Forma muy compleja de acción popular directa que subyace en el trabajo de Piccato.

En la defensa de los mecanismos de subsistencia, robar fue sólo una alternativa para mitigar la escasez en el año del hambre. Tropas zapatistas, pandilleros y turbas aprovechaban los recursos que estaban a su alcance según sus necesidades. Los motines, los asaltos y el robo a las tiendas de alimentos y artículos de primera necesidad manifestaron el hambre del pueblo. Pero los mecanismos de subsistencia que proveía el delito se desarrollan en la ciudad no sólo por la necesidad y la escasez, sino también por la expansión de un mercado dinámico para conseguir dinero, una vez que el orden fue recuperado por los sonorenses.

Si bien las estadísticas históricas mexicanas de la criminalidad han sido objeto de recelo, por la deficiencias metodológicas y conceptuales, Piccato no renuncia al uso de esta fuente para su análisis. Así, muestra algunos aspectos del perfil del criminal urbano y presta atención a ciertas correlaciones que marcan la tendencia de las políticas públicas, por ejemplo, cuando el gasto del Estado (en el Porfiriato) invirtió en jueces y fiscales y creció el número de personas arrestadas o sentenciadas, o cuando el de- 
bilitamiento del poder represivo del Estado se tradujo en una reducción de la delincuencia alrededor de 1920, o bien como una continuidad con el encierro de los vagos en el siglo xix se advierte que los artesanos fueron un grupo vulnerable frente a las políticas de control del Estado. Éstos entre otros resultados que abren hipótesis para caminos poco explorados en el análisis específico de correlaciones entre condiciones económicas y otros delitos, además del hurto.

Una cuidadosa traducción hace relucir la pertinencia de la seria investigación que le dio forma al trabajo original publicado en inglés y que ha sentado las bases para otros temas en los que ha incursionado el autor: el honor, sus transgresiones, la sociedad civil, la prevención del crimen y la opinión pública. Ciudad de sospechosos invita al diálogo, no sólo a quienes han trabajado el tema del crimen y el castigo, sino también al que busca una renovación temática, por ejemplo en la historiografía de los últimos años que ha estudiado la construcción de identidades en el barrio o la delincuencia como parte del problema de la modernización urbana.

Para concluir, valga una reflexión última sobre la pertinencia del libro. Si bien el autor no tuvo el propósito explícito de leer la historia del crimen en términos del presente, la contribución de este importante estudio reside en la indudable capacidad de tejer puentes entre la aplicación del saber científico en beneficio de la sociedad. El libro de Pablo Piccato nos ayuda a reflexionar sobre la pertinencia de la historia en el análisis de las políticas públicas. Ojalá que en las próximas reformas penitenciarias, de campañas en favor del jurado popular y en la creación de nuevos cuerpos policiacos, entre otros temas que hoy se discuten, las prácticas para prevenir la delincuencia integren explicaciones más complejas y no se aboquen a reducir los índices de criminalidad, sino a revertir los estragos que amenazan la incertidumbre de una población que vive bajo sospecha, porque tal parece que las propuestas que pudiéramos haber hecho para mitigar los efectos del crimen en la ciudad hace rato que han dejado de funcionar.

Me resta asegurar que ningún lector de este libro se verá defraudado por sus páginas y que el asalto a la reflexión será sin violencia. Quien quiera algunas respuestas sobre el crimen y su tratamiento deberá, coactivamente, leer el libro y obtendrá como única sentencia plantearse la enorme complejidad de un fenómeno social que Pablo Piccato expone tan logradamente. 
María Dolores Lorenzo-Río

El Colegio Mexiquense, A.C. mlorenzo@cmq.edu.mx

María Dolores Lorenzo-Río. Es profesora-investigadora de El Colegio Mexiquense. Obtuvo el grado de doctora en historia por El Colegio de México. Su trabajo de investigación ha incursionado en la historia social de la asistencia. En 2010 la Academia Mexicana de Ciencias le otorgó el premio a la mejor tesis de humanidades. Entre sus publicaciones se encuentran: El Estado como benefactor. Los pobres y la asistencia pública en la ciudad de México, 1877-1905, El Colegio de México, México (2011); "Segregación social y espacios de entretenimiento en la ciudad de México", en Mario Barbosa y Salomón González (coords.), Problemas de la urbanización en el valle de México, 1810-1910. Un homenaje visual en la celebración de los centenarios, Universidad Autónoma Metropolitana, México, pp. 227-255 (2009); "Una ojeada a la indigencia. Los proyectos asistenciales a finales del siglo XIX ACJ”, en Jorge Villalobos, Silvia Arrom, Mercedes Alanís, Esther Espeja, Mario Luis Fuentes y Gloria Guadarrama (eds.), Filantropía y acción solidaria en la historia de México, Centro Mexicano para la Filantropía-El Equilibrista, pp. 87-117 (2010); "Una lotería para los pobres", Difusión de la Academia y la Cultura, año 7, 1 (22), Escuela Nacional Preparatoria-Universidad Nacional Autónoma de México, México, pp. 61-64 (2008). Ha recibido el apoyo de las becas de Conacyt y del Inehrm, además del Premio Fernando Rosenzweig en 2001 a la mejor tesis de maestría en historia económica. Paralelamente a su trabajo de investigación se ha desempeñado como docente, impartiendo cursos en licenciatura y maestría en el CIDE, ITESM, UIA, la UNAM y actualmente en El Colegio Mexiquense. 